\title{
La motivación del alumnado derivada de la realización de prácticas en contextos reales
}

\section{Paula Santiago Martín de Madrid}

Doctora en Bellas Artes. Profesora de la Facultad de Bellas Artes de la Universitat Politècnica de València. Investigadora en el Centro de Investigación Arte y Entorno CIAE-UPV (masanma6@pin.upv.es)

\begin{abstract}
Based on the case of one of the subjects that are teachers responsible we want to use some of the practices engaged in order to analyze the implementation of specific teaching methods so evaluate its impact not only on the motivation of our students, but also in regard to the fulfillment of their professional expectations. Therefore, in the cases included in this text, motivation and active participation are fundamental elements in the process of teaching and learning reason why a special importance is given to the following factors: the use of different methodologies in teaching, collaborative involvement of students, setting up channels of communication and the establishment of relations between the acquisition of knowledge and its application in real contexts.
\end{abstract}

Keywords: motivation, skills, training, methodology, collaborative work, Fine Arts.

\section{Resumen}

Partiendo del caso concreto de una de las asignaturas de las que somos responsables docentes deseamos utilizar algunas de las prácticas llevadas a cabo en la misma con el objetivo de analizar la aplicación de determinadas metodologías didácticas para así valorar su repercusión no sólo en la motivación de nuestro alumnado, sino también en lo concerniente al cumplimiento de sus expectativas profesionales. Por tanto, en los casos incluidos en el presente texto, la motivación y la participación activa se constituyen como elementos fundamentales en el proceso de enseñanzaaprendizaje, razón por la que se otorga una especial relevancia a los siguientes factores: el uso de diferentes metodologías en la docencia, la implicación colaborativa del alumnado, la configuración de canales de comunicación y el establecimiento de relaciones entre la adquisición de conocimiento y su aplicación en contextos reales.

Palabras clave: motivación, competencias, formación, metodología, trabajo colaborativo, Bellas Artes. 


\section{Introducción}

La asignatura Presentación y divulgación de obras de arte tiene como finalidad básica aproximar al alumno/a a las estrategias de postproducción de la obra de arte y a la realidad artística actual dotándole de una serie de capacidades profesionales que le permitan desarrollar proyectos expositivos coherentes con el marco social, institucional y de mercado predominante.

En este contexto, uno de los objetivos de la asignatura es el de formar a los estudiantes en aquellos aspectos relativos al diseño, organización, gestión y montaje expositivo dándoles a conocer la metodología básica para la presentación y divulgación de la obra de arte. Asimismo, la materia desea familiarizar al alumnado con los distintos agentes y canales que intervienen tanto en el desarrollo expositivo, como en el de eventos culturales. En este sentido, se pretende desarrollar en nuestros alumnos y alumnas unas capacidades que les permitan resolver problemas relacionados con el montaje técnico expositivo y con la gestión expositiva en función de la infraestructura del lugar de exhibición y el contexto social en el que se desarrolla.

Finalmente, se ha de destacar como aspecto a tener en cuenta la formación en todo un conjunto de cuestiones relacionadas con la realidad del mercado y con la demanda social, hecho que pone de relieve la necesidad de articular y potenciar un desarrollo curricular coherente.

En este contexto y ante las numerosas posibilidades de metodologías docentes aplicables en la enseñanza, nos planteamos las ventajas e inconvenientes que cada una de ellas puede presentar en relación a la materia a impartir así como en relación al perfil de nuestro alumnado. Asimismo, a la hora de planificar nuestra docencia y seleccionar las metodologías a utilizar, partimos del hecho de que el mismo método no siempre ha de ser el mejor en todas las situaciones y contextos (Fernández, 2006).

\section{Objetivos}

Algunos de los objetivos básicos de los que partimos para planificar la docencia en relación a potenciar la participación y motivación del alumnado se podrían resumir en los siguientes:

- Estimular la motivación, iniciativa y creatividad del alumnado.

- Fomentar el trabajo participativo y el juicio crítico.

- Desarrollar el sentido de responsabilidad.

- Impulsar la toma de decisiones.

- Captar la atención y la implicación.

- Activar el pensamiento crítico y potenciar la curiosidad.

- Optimizar la capacidad de respuesta en el contexto real.

(c)) EY-NC-ND 2016, Universitat Politècnica de València 
- Fomentar la participación en actividades extrauniversitarias.

- Desarrollar las relaciones con agentes externos a la institución universitaria.

En nuestra opinión, mediante las metodologías expuestas en el presente texto, hemos contribuido y ayudado al alumnado a situarse como protagonista de su aprendizaje (García y Amante, 2006) ya que partimos del hecho de que los procesos de aprendizaje requieren la utilización de metodologías docentes, definidas como el conjunto de oportunidades y condiciones que se ofrecen a los estudiantes para promover el aprendizaje.

Si partimos de los resultados obtenidos en los cursos académicos impartidos en la asignatura, se considera que el alumnado desarrolla de manera más óptima su aprendizaje $\mathrm{y}$, por tanto, su motivación se ve notablemente incrementada- si son incorporados algunos de los elementos contemplados en las prácticas que desarrollamos en los epígrafes siguientes y que tienen una relación directa con la incorporación de los resultados derivados de las mismas en contextos reales.

Al objeto de ilustrar esta hipótesis, han sido seleccionadas tres prácticas desarrolladas en los últimos cursos en el marco de la asignatura mencionada -Juicio crítico, Propuesta expositiva colectiva y Lectura y análisis de texto en grupo- que responden a esta premisa. Cabe señalar que para cada una de las tres propuestas planteadas se ha partido de metodologías docentes diferenciadas como son el juego de rol, la realización de proyectos y la lectura en puzzle, si bien la selección de trabajos responde al hecho de que en todos los casos se trata de trabajos realizados de forma cooperativa y grupal.

Para la implementación del trabajo en grupo (Fernández, 2006) en el marco de la asignatura, y concretamente en el desarrollo de las prácticas expuestas en el presente texto, partimos del hecho de que se trata de una estrategia que permite desarrollar competencias profesionales y habilidades imprescindibles en un escenario real. Sabemos que el trabajo cooperativo refuerza la motivación, ya que la consecución de los objetivos del grupo se encuentra estrechamente vinculada a la consecución de los objetivos individuales. En este sentido, a continuación se exponen los planteamientos y resultados obtenidos en cada uno de los casos seleccionados.

\section{Juicio crítico}

La formulación de un juicio de carácter crítico conlleva, entre otros mecanismos, la utilización de conocimientos adquiridos, la capacidad para relacionar aspectos diferentes y la introducción de cuestionamientos y preguntas que pongan a prueba las propias afirmaciones $-\mathrm{y}$ ello no tanto para refutar como para obtener un mayor conocimiento del objeto en cuestión-.

A través de la propuesta planteada se reclama al alumnado una participación activa que le exige involucrarse directamente en el tema e interesarse por el mismo. El objetivo primordial del trabajo va dirigido a que nuestros estudiantes sean conscientes de que cualquier toma de posición requiere no sólo de una argumentación lógica y de una cierta experiencia, sino también del uso y renovación de conocimientos aprehendidos.

(cc) BY-NC-ND 2016, Universitat Politècnica de València

Congreso In-Red (2016) 
Paralelamente, mediante esta actividad se desea fomentar el desarrollo de la capacidad crítica al margen de descalificaciones y/o críticas de carácter personal. Finalmente, se pretende fomentar la motivación mediante la incorporación de los resultados en un contexto real, así como promover la capacidad de iniciativa.

\subsection{Planteamiento de la actividad}

Aprovechando una convocatoria real de un concurso de arte, se solicita al alumnado la aportación de una obra que más tarde será enviada a dicho certamen. A partir de esta situación, durante una sesión de clase se estructura a los alumnos y alumnas en grupos que adoptan el rol de los miembros del jurado que han de valorar las piezas realizadas. Cada grupo ha de llevar a cabo la selección de tres obras a las que de manera consensuada tiene que otorgar un primero, un segundo y un tercer premio. La selección, lógicamente, tiene que efectuarse de forma razonada y argumentada.

Dentro de este contexto, cada miembro del grupo expone las razones de su selección, efectuando un especial hincapié en los argumentos en los que la misma se basa. Volvemos a insistir en el hecho de que la decisión última responde a una solución de consenso que parte del propio grupo. Para que la decisión se articule en función de razones coherentes se tendrán en consideración: los aspectos conceptuales planteados, la resolución técnica que posee la obra, la presentación de la misma y los elementos innovadores que presenta.
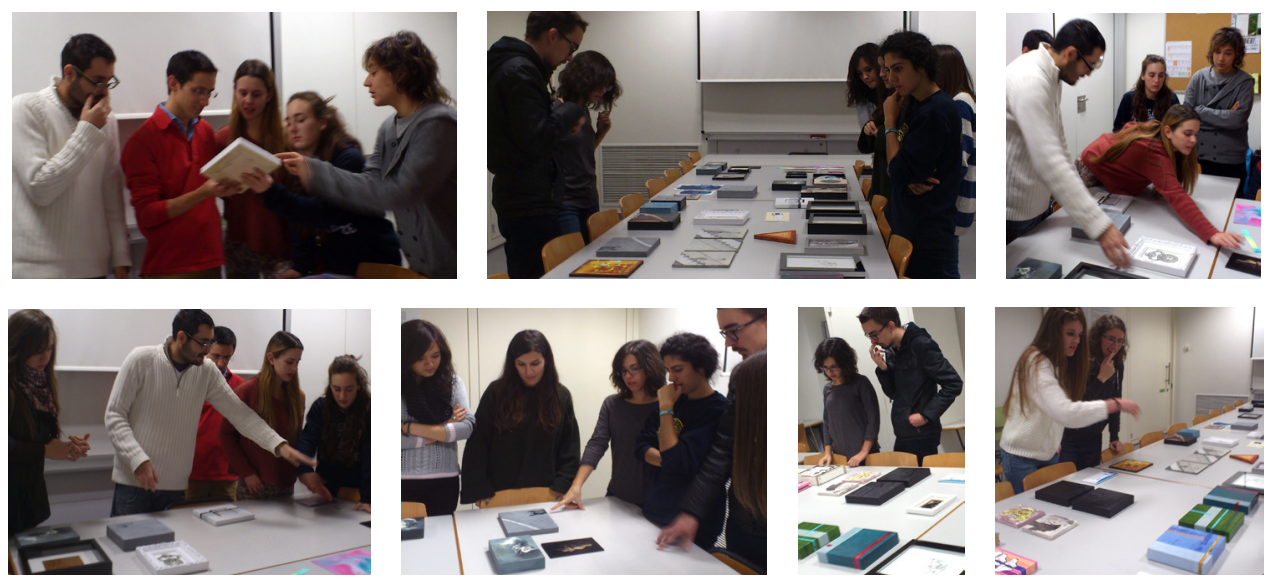

Fig. 1 Alumnado en una práctica basada en la metodología Juego de rol para la práctica "Juicio crítico"

Curso académico 2014-2015

Para la defensa de los trabajos se ha de hacer un uso complejo de los conocimientos adquiridos, de ahí que la propuesta permite la actualización de aspectos formativos esenciales mediante la transformación e incorporación de los mismos a nuestra argumentación a favor de los trabajos objeto de nuestra crítica.

(cc) EY-NC-ND 2016, Universitat Politècnica de València

Congreso IN-RED (2016) 
Una vez celebrada la sesión de aula, el alumnado remite, de forma voluntaria, la obra realizada al concurso, ya que la misma ha sido elaborada siguiendo las pautas y premisas planteadas en la convocatoria del mismo. Por otro lado, la misma se plantea en un momento del curso previo a la finalización del plazo para la presentación de trabajos en la convocatoria pública.

\subsection{Resultados derivados de la práctica}

Durante los cursos en los que ha sido llevada a cabo la actividad, un buen número de obras enviadas han sido seleccionadas por el jurado del mencionado concurso para la celebración de una exposición. De este hecho se desprende que la selección realizada por el jurado profesional, en numerosas ocasiones ha coincidido con la selección que previamente había realizado el colectivo de alumnado que adoptaba el papel de jurado en el juego de rol celebrado en el aula.

Por otro lado, en todas las ocasiones, alguna de las piezas remitidas ha obtenido una distinción que, a su vez, tenía coincidencia con los hipotéticos premios otorgados por el colectivo de alumnos en su papel de jurados. En este sentido, cabe hacer especial alusión a la obtención de diversos premios, entre los que figura un primer premio obtenido por uno de nuestros alumnos en una convocatoria que contó con una relevante participación de aproximadamente 500 piezas y que, a su vez se dotó con un importante premio económico.

Los mencionados resultados obtenidos en cursos precedentes, favorece de una manera notable la motivación del alumnado de futuros cursos. Asimismo, y partiendo de uno de los objetivos básicos de la asignatura en relación al desarrollo curricular, esta práctica sienta, en numerosos casos, un precedente para posteriores participaciones en convocatorias públicas a título personal. De hecho, tal y como ya hemos indicado, el envío a la convocatoria pública se realiza de forma voluntaria, si bien la participación por parte del alumnado es muy elevada ya que prácticamente el $100 \%$ del mismo remite la obra realizada.

\section{Propuesta exposición colectiva}

Programar una exposición conlleva la realización de una serie de tareas entre las que podemos destacar:

- Elaborar una propuesta/dossier con los contenidos de la exposición.

- Realizar tareas de gestión en colaboración con agentes externos.

- Estudiar el espacio expositivo susceptible de albergar nuestra exposición.

- Diseñar el material divulgativo de la muestra.

Nuestro interés en este ejercicio radica especialmente en motivar al alumnado para la realización de proyectos comprometidos y coherentes con una realidad social concreta, para lo que se solicita una argumentación que justifique la muestra expositiva. Asimismo, se

(cc) EY-NC-ND 2016, Universitat Politècnica de València

Congreso In-Red (2016) 
trata de aproximar al alumnado a una experiencia real que potencie su interés por investigar en una temática, así como por ampliar sus expectativas más allá del marco universitario.

\subsection{Planteamiento de la actividad}

Para la presente actividad se plantea al alumnado, que trabajará en grupos, elaborar una propuesta para la realización de una exposición en un espacio real. En esta ocasión, nos centramos en un proyecto y/o conjunto de obras que sean susceptibles de dar lugar a una muestra expositiva coherente con una temática y/o hecho concreto así como con las técnicas y metodologías artísticas que definen el perfil de cada uno de los integrantes de los diferentes grupos. La propuesta se estructura incluyendo como mínimo los siguientes aspectos:

- Introducción

- Desarrollo conceptual de la propuesta

- Imágenes acompañadas de ficha técnica

- Características técnicas y de montaje

- Propuesta de material divulgativo

Asimismo, la actividad conlleva la realización de un trabajo de campo por parte del alumnado que incluye visitar y estudiar los espacios expositivos propuestos, así como gestionar la muestra con los agentes que intervienen en el desarrollo de la misma. Es recomendable recabar información en la sala sobre aspectos relacionados con el sistema de montaje así como tomar imágenes fotográficas de la sala al efecto de poder llevar a cabo simulaciones espaciales. En este sentido, cabe señalar la labor del docente que facilita un listado de espacios previamente concertados con instituciones públicas y/o privadas.

\subsection{Resultados derivados de la práctica}

En el presente caso hemos escogido como ejemplo, una de las propuestas efectuada durante el curso 2015-2016 bajo el título Espacio disponible y que se materializó en una exposición fotográfica en la que la urbe y su sostenibilidad se configuró como referente del proyecto presentado por uno de los grupos que, a su vez, partía de la noción de ciudad para la realización de sus trabajos creativos.

En la exposición, que tuvo lugar en un espacio expositivo dependiente del Ayuntamiento de Valencia, cinco alumnos y alumnas ilustran con su proyecto las heterogéneas maneras en que la amplia categoría de espacio puede ser abordada mediante la práctica fotográfica, con imágenes que van desde la crítica social del espacio urbano a la memoria personal del mismo, la definición del espacio a través de la propia estética compositiva de la obra o la reivindicación de la memoria histórica del espacio geográfico.

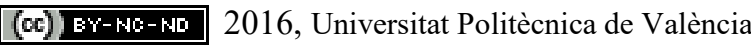



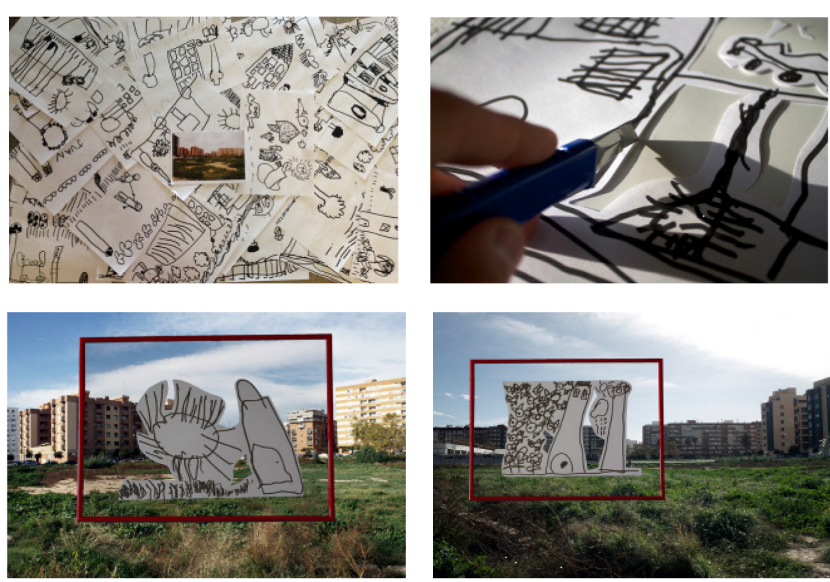

Fig. 2 Imágenes del proyecto "Ninguno pedirá un parking" realizado por Gabriele Menconi para la exposición titulada "Espacio disponible". Curso académico 2015-2016

En la actividad propuesta, los trabajos agrupados en la muestra expositiva son vehículos capaces de trasladarnos a un discurso más amplio y/o a una teoría que estaría situada más allá del juicio estético o visual. En este sentido, uno de los alumnos participantes en esta propuesta presentó el trabajo titulado Ninguno pedirá un parking que planteaba una reflexión sobre el concepto de espacio. Para el desarrollo del mismo decidió trabajar con un espacio real -un área urbana abandonada situada detrás de una serie de edificios en el barrio de Alfahuir de Valencia- y con uno que fue definido como imaginario.

En este contexto, el alumno propone una posible situación futura para lo que solicitó la visión de un colectivo de niños que aportaran soluciones para el citado espacio. Para ello realizó las gestiones pertinentes con el CEIP Max Aub de Valencia al objeto de poder llevar a cabo la propuesta con un colectivo de niños de 4 años que, según su punto de vista, proporcionarían ideas libres de prejuicios y exigencias particulares con soluciones desinteresadas fruto de la imaginación.

El proyecto final, que incorporaba las propuestas de los niños, se materializó en un conjunto de obras que fueron expuestas mediante una instalación en el EIC Constatí LLombart del Ayuntamiento de Valencia. Por otro lado, la revista de arquitectura y paisaje NipMagazine se ha interesado por esta intervención artística proponiendo a su autor presentar un artículo con los contenidos de la propuesta.

En este caso nos interesa subrayar no solo la motivación del alumnado para la realización de sus propuestas, sino también la capacidad de iniciativa de un porcentaje elevado del mismo. Los resultados del presente proyecto responden a una aportación que parte de la iniciativa personal para implicarse más allá de la demanda que propone la actividad plantada. 


\section{Lectura y análisis de texto en grupo}

La presente actividad tiene como finalidad aproximar al alumnado a piezas artísticas realizadas en un contexto social y político concreto. Por lo general, las obras a analizar responden a proyectos adaptados a una situación y a un espacio específico y todas ellas han suscitado algún tipo de debate público y social. Para llevar a término la actividad se ha seleccionado un texto que aborda la problemática de la gentrificación mediante ocho capítulos que analizan las obras specific site/specific time de diversos artistas de reconocido prestigio internacional (Candela, 2007).

\subsection{Propuesta}

Para la realización de esta actividad, que se lleva a cabo en el aula, se utiliza la metodología docente del puzzle o rompecabezas. En función de la misma, el alumnado queda agrupado en ocho equipos, procediéndose de la siguiente manera: 1) Se asigna un capítulo -para su estudio compartido- a cada grupo. 2) Se realiza una puesta en común en el aula tomando como punto de partida los aspectos señalados en una ficha facilitada por el docente. 3) Cada equipo narra al resto de compañeros y compañeras los contenidos más relevantes haciendo especial alusión al contexto social en el que éstas fueron realizadas. 4) Las intervenciones de los diferentes equipos son sometidas a valoración por el resto de equipos.

Partiendo de las ideas apuntadas en el aula y en las anteriores actividades realizadas a lo largo del curso, se propone diseñar a cada uno de los grupos una intervención specific site/specific time tomando como referente un espacio concreto de la ciudad o problemática social de actualidad.
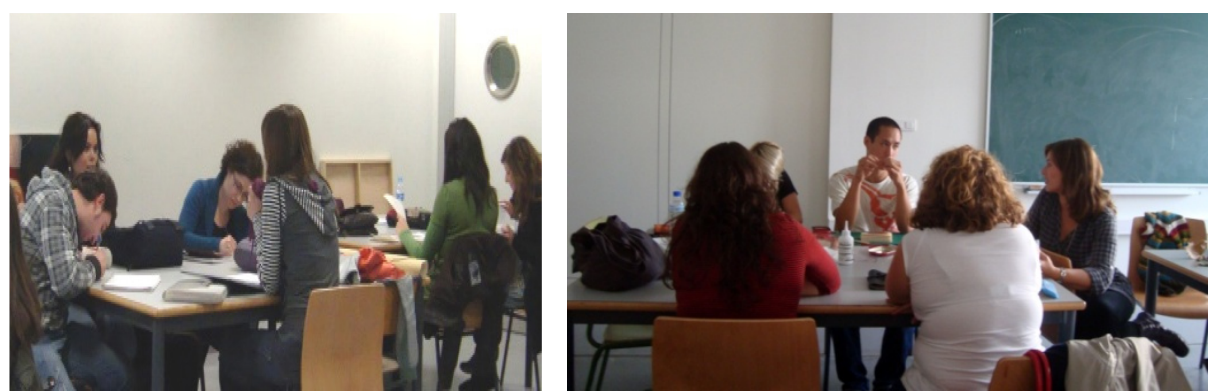

Fig. 3 Alumnado en una práctica basada en la metodología

Lectura en puzzle para la práctica "Lectura y análisis de texto en grupo"

Curso académico 2012-2013

El ejercicio es evaluado atendiendo a aspectos como la comprensión de los conceptos, la capacidad de síntesis, la presentación formal de los contenidos, la expresión y capacidad comunicativa y la creatividad y originalidad del proyecto presentado. Junto a ello, también se tienen en consideración las valoraciones críticas realizadas por el resto de alumnos y alumnas. 


\subsection{Resultados derivados de la práctica}

En la presente práctica, la demanda realizada al alumnado supone la elaboración de una propuesta que parte del estudio de una realidad social concreta desde el análisis de la temática mediante la lectura en grupo de un texto. La misma, al contrario de lo que sucedía en los dos casos precedentes, no implica la intervención o exposición en escenarios públicos. No obstante, en relación al fomento de la motivación y la capacidad de iniciativa en nuestro alumnado, nos interesa poner de relieve las derivas que la resolución de la presente actividad ha tenido durante los últimos cursos.

En diversos casos, los proyectos realizados han sido presentados, y seleccionados en algún caso, en convocatorias públicas de arte público. Asimismo, durante el curso académico 2012-13, el colectivo integrante de uno de los grupos decidió ponerse en contacto con el autor -artista de reconocido prestigio internacional- de la obra que había sido estudiada mediante la metodología de puzzle, al objeto de demandar su opinión al respecto del proyecto que habían realizado. La respuesta fue muy positiva, incluyendo una felicitación por la iniciativa y remitiendo al grupo un valioso material audiovisual firmado por su autor.

\section{Resultados}

Los resultados, que para el alumnado ha conllevado la realización de las prácticas incluidas en el presente texto, ya han sido expuestas en los apartados anteriores. Aquí nos centraremos en una serie de datos derivados de diferentes modelos de encuesta llevadas a cabo en el marco de la asignatura, al objeto de elaborar conclusiones relativas a la aceptación que la aplicación de metodologías activas en contextos reales tiene entre nuestro alumnado, así como la capacidad de motivación que las mismas poseen.

\subsection{Datos cuantitativos derivados de encuestas realizadas al alumnado}

La asignatura a la que se hace alusión en el presente texto se ha impartido en el Departamento de Pintura de la Facultad de Bellas Artes de Valencia desde el curso académico 2008-2009. Durante seis cursos formó parte del grupo de asignaturas optativas a las que el alumnado de Licenciatura en Bellas Artes podía acceder, pasando en el curso 2013-2014 a formar parte del Plan de Estudios del Grado en Bellas Artes. La misma ha contado durante los últimos cuatro años con una matrícula media de 42.5 alumnos/as, aspecto que en nuestra opinión pone de relieve la buena acogida de la misma dado su carácter optativo.

Con carácter anual, el ICE-UPV realiza una encuesta al alumnado matriculado en la asignatura mediante la que se le solicita información al respecto de la práctica docente del profesorado y en la que se contemplan los siguientes ítems: 1) Dominio de la materia 2) Resolución de dudas y cuestiones relacionadas con la materia 3) Información clara sobre la materia al inicio del curso 4) Programación y ritmo de las clases 5) Metodologías

(cc) EY-NC-ND 2016, Universitat Politècnica de València

Congreso In-Red (2016) 
empleadas y actividades realizadas 6) Materiales utilizados 7) Clima de trabajo y fomento de la participación 8) Manera de explicar 9) Capacidad global del profesorado 10) Materiales docentes disponibles en la plataforma PoliformaT.

Tabla 1. Resultados de las Encuestas de Evaluación de la Docencia realizadas por el Instituto de Ciencias de la Educación UPV para la asignatura

\begin{tabular}{|c|c|c|c|c|c|c|c|c|c|}
\hline CURSO & $\begin{array}{c}2008 \\
2009 \\
\text { Licenc }\end{array}$ & $\begin{array}{c}2009 \\
2010 \\
\text { Licenc }\end{array}$ & $\begin{array}{c}2010 \\
2011 \\
\text { Licenc }\end{array}$ & $\begin{array}{c}2011 \\
\text { Licenc }\end{array}$ & $\begin{array}{c}2012 \\
\text { Licenc }\end{array}$ & $\begin{array}{c}2013 \\
2014 \\
\text { Licenc }\end{array}$ & $\begin{array}{c}2013 \\
2014 \\
\text { Grado }\end{array}$ & $\begin{array}{c}2014 \\
2015 \\
\text { Grado }\end{array}$ & $\begin{array}{c}2015 \\
2016 \\
\text { Grado }\end{array}$ \\
\hline $\begin{array}{c}\text { VALORAC. } \\
\text { MEDIA }\end{array}$ & 7.98 & 8.52 & 8.32 & 8.68 & 6.61 & 9.06 & 8.01 & 8.10 & Pte. \\
\hline $\begin{array}{c}\text { Ítem 5 } \\
\text { Metodologías }\end{array}$ & 8.41 & 8.25 & 7.90 & 8.64 & 6.15 & 8.47 & 7.59 & 8.02 & Pte. \\
\hline $\begin{array}{c}\text { Ítem 7 } \\
\text { F.Participación }\end{array}$ & 9.32 & 8.63 & 8.47 & 8.86 & 7.04 & 9.58 & 8.52 & 8.44 & Pte. \\
\hline
\end{tabular}

Durante el citado periodo, los datos derivados de las encuestas ponen de relieve la buena acogida que las metodologías (Ítem 5) llevadas a cabo han tenido. Si bien los datos son susceptibles de ser mejorados, se observa que el clima de trabajo y el fomento a la participación (Ítem 7) en el marco de la asignatura se valora por encima de la media global obtenida por el/la docente en todos los cursos analizados.

Por otro lado, si bien se han seleccionado tres casos, que consideramos especialmente significativos por los resultados obtenidos fuera del contexto universitario, en el marco de la asignatura y en el transcurso del periodo señalado se han venido planteando diferentes actividades -actualmente diez- con diferentes niveles de dificultad que son resueltas mediante la aplicación de diversas metodologías docentes. Asimismo, el alumnado lleva a cabo un portafolio razonado en el que incorpora los resultados de cada una de las prácticas con una reflexión que incluye el grado de satisfacción de las mismas. De los datos obtenidos, en los nueve cursos analizados, se desprende que prácticamente la totalidad del alumnado prefiere realizar prácticas cuyos resultados sean susceptibles de llevarse a cabo en un escenario real y el resto se manifiesta indiferente. Asimismo, en los últimos años se observa un incremento en el interés por esta tipología de prácticas.

Tabla 2. Resultados derivados del portafolio de la asignatura. Porcentajes de alusión a la preferencia de realización de prácticas en contextos reales

\begin{tabular}{|c|c|c|c|c|c|c|c|c|c|}
\hline CURSO & $\begin{array}{c}2008 \\
2009 \\
\text { Licenc }\end{array}$ & $\begin{array}{c}2009 \\
\text { Licenc }\end{array}$ & $\begin{array}{c}2010 \\
2011 \\
\text { Licenc }\end{array}$ & $\begin{array}{c}2011 \\
2012 \\
\text { Licenc }\end{array}$ & $\begin{array}{c}2012 \\
2013 \\
\text { Licenc }\end{array}$ & $\begin{array}{c}2013 \\
2014 \\
\text { Licenc }\end{array}$ & $\begin{array}{c}2013 \\
2014 \\
\text { Grado }\end{array}$ & $\begin{array}{c}2014 \\
2015 \\
\text { Grado }\end{array}$ & $\begin{array}{c}2015 \\
\text { Grado }\end{array}$ \\
\hline $\begin{array}{c}\% \\
\text { PREF. } \\
\text { CONT.REAL }\end{array}$ & 80 & 85 & 83 & 90 & 89 & 90 & 92 & 91 & 95 \\
\hline $\begin{array}{c}\% \\
\text { INDIFER. }\end{array}$ & 20 & 15 & 17 & 10 & 11 & 10 & 8 & 9 & 5 \\
\hline
\end{tabular}

(c)) EY-NC-ND 2016, Universitat Politècnica de València 
Para finalizar, cabe señalar que coincidiendo con el último día de clase se realiza una encuesta al alumnado al que se responde de forma anónima. En el mismo se solicita información al respecto de la materia y del docente con la limitación de un folio en blanco sin ajustarse a un cuestionario tipo, con el objeto de dar mayor libertad en las respuestas. La citada encuesta tan solo incluye cuatro preguntas:

1. ¿Qué es lo que más te ha gustado de la asignatura? (actividades que han dado respuesta a tus expectativas, actividades que te han ayudado en tu formación profesional, colaboración con el resto de compañeros/as, etc.)

2. ¿Qué es lo que menos te ha gustado de la asignatura? (actividades que no han dado respuesta a tus expectativas, actividades que no te han ayudado en tu formación profesional, reducida colaboración con el resto de compañeros/as, etc.)

3. ¿Qué es lo que más te ha gustado del profesor/a? (metodologías docentes utilizadas, capacidad para motivar, forma de explicar, accesibilidad, etc.)

3. ¿Qué es lo que menos te ha gustado del profesor/a? (metodologías docentes utilizadas, reducida capacidad para motivar, forma de explicar, reducida accesibilidad, etc.)

En todos los cursos analizados, en las respuestas dadas a la primera pregunta el $100 \%$ del alumnado siempre ha incorporado alguna de las prácticas llevadas a cabo en contextos reales. Por el contrario, las respuestas dadas a la segunda pregunta en ningún caso incorporan una práctica de estas características. En la misma dirección y en relación a la práctica docente contenida en la tercera y cuarta pregunta, la mayoría del alumnado se inclina por poner en valor las metodologías utilizadas y el fomento de la motivación.

Tabla 3. Resultados derivados de la encuesta final de la asignatura. Porcentajes de alusión a la realización de prácticas en contextos reales

Lo que más me ha gustado de la asignatura

\begin{tabular}{|c|c|c|c|c|c|c|c|c|c|}
\hline CURSO & $\begin{array}{c}2008 \\
2009 \\
\text { Licenc } \\
\end{array}$ & $\begin{array}{c}2009 \\
2010 \\
\text { Licenc }\end{array}$ & $\begin{array}{r}2010 \\
2011 \\
\text { Licenc }\end{array}$ & $\begin{array}{r}2011 \\
2012 \\
\text { Licenc } \\
\end{array}$ & $\begin{array}{c}2012 \\
2013 \\
\text { Licenc } \\
\end{array}$ & $\begin{array}{c}2013 \\
2014 \\
\text { Licenc } \\
\end{array}$ & $\begin{array}{c}2013 \\
2014 \\
\text { Grado } \\
\end{array}$ & $\begin{array}{c}2014 \\
2015 \\
\text { Grado } \\
\end{array}$ & $\begin{array}{c}2015 \\
2016 \\
\text { Grado } \\
\end{array}$ \\
\hline$\%$ & 100 & 100 & 100 & 100 & 100 & 100 & 100 & 100 & 100 \\
\hline
\end{tabular}

Lo que más me ha gustado de la asignatura

\begin{tabular}{|c|c|c|c|c|c|c|c|c|c|}
\hline CURSO & $\begin{array}{c}2008 \\
2009 \\
\text { Licenc }\end{array}$ & $\begin{array}{c}2009 \\
2010 \\
\text { Licenc }\end{array}$ & $\begin{array}{c}2010 \\
2011 \\
\text { Licenc }\end{array}$ & $\begin{array}{c}2011 \\
2012 \\
\text { Licenc }\end{array}$ & $\begin{array}{c}2012 \\
2013 \\
\text { Licenc }\end{array}$ & $\begin{array}{c}2013 \\
2014 \\
\text { Licenc }\end{array}$ & $\begin{array}{c}2013 \\
2014 \\
\text { Grado }\end{array}$ & $\begin{array}{c}2014 \\
2015 \\
\text { Grado }\end{array}$ & $\begin{array}{c}2015 \\
2016 \\
\text { Grado }\end{array}$ \\
\hline$\%$ & 0 & 0 & 0 & 0 & 0 & 0 & 0 & 0 & 0 \\
\hline
\end{tabular}

(cc) EY-NC-ND 2016, Universitat Politècnica de València

Congreso In-Red (2016) 
Tabla 3. Resultados derivados de la encuesta final de la asignatura. Porcentajes de alusión a las metodologías utilizadas y capacidad de motivación del profesor/a

Lo que más me ha gustado del profesor/a

\begin{tabular}{|c|c|c|c|c|c|c|c|c|c|}
\hline CURSO & $\begin{array}{c}2008 \\
2009 \\
\text { Licenc }\end{array}$ & $\begin{array}{c}2009 \\
2010 \\
\text { Licenc }\end{array}$ & $\begin{array}{c}2010 \\
2011 \\
\text { Licenc }\end{array}$ & $\begin{array}{c}2011 \\
2012 \\
\text { Licenc }\end{array}$ & $\begin{array}{c}2012 \\
2013 \\
\text { Licenc }\end{array}$ & $\begin{array}{c}2013 \\
2014 \\
\text { Licenc }\end{array}$ & $\begin{array}{c}2013 \\
2014 \\
\text { Grado }\end{array}$ & $\begin{array}{c}2014 \\
2015 \\
\text { Grado }\end{array}$ & $\begin{array}{c}2015 \\
2016 \\
\text { Grado }\end{array}$ \\
\hline $\begin{array}{c}\% \\
\text { METODOL. }\end{array}$ & 82 & 80 & 80 & 75 & 70 & 85 & 85 & 83 & 85 \\
\hline $\begin{array}{c}\% \\
\text { MOTIVAC. }\end{array}$ & 83 & 85 & 87 & 80 & 80 & 88 & 87 & 85 & 87 \\
\hline
\end{tabular}

\subsection{Valoración global}

En relación a los mecanismos utilizados para motivar al alumnado de cara a mantener una fluida comunicación, podemos señalar que los mismos derivan directamente de las metodologías empleadas en el proceso de enseñanza-aprendizaje (Ibernon y Medina, 2008). Al respecto, no hay que olvidar que en los planteamientos de actividades constatamos que, bien porque su elaboración y resolución se lleva a cabo de forma cooperativa, bien porque las mismas son expuestas en el aula, se abre un espacio en el que el alumnado intercambia ideas, criterios, opiniones, etc. En este sentido, cabe señalar como elemento muy positivo el hecho de que las correcciones realizadas de forma conjunta en el contexto del aula, ayudan a mejorar la comunicación, dado que permiten el fortalecimiento de lazos entre los miembros integrantes del grupo.

Con respecto a las metodologías utilizadas, el juego de rol utilizado en el primer ejemplo supone una práctica de gran ayuda a la hora de motivar al alumnado ya que requiere adoptar la posición de experto en una materia concreta, utilizar una terminología propia del papel asumido, desarrollar una mirada crítica, etc. En el caso expuesto, los alumnos y alumnas asumen el papel de un crítico de arte que desempeña su función dentro un jurado, razón por la que las intervenciones para valorar las diferentes obras, han de estar plenamente argumentadas desde el rol asumido.

En el segundo caso, se hace uso de la elaboración de proyectos que supone una metodología muy extendida en la dinámica educativa de Bellas Artes. Esta práctica, en la que se lleva a cabo un proyecto expositivo, permite al alumnado desarrollar, tanto en lo que se refiere a la organización como a la aplicación, los conceptos aprendidos. Por otro lado, mediante el proyecto se estimula la iniciativa y la creatividad profundizando en el sentido de responsabilidad. Al mismo tiempo, la exposición de los resultados en un contexto real ayuda al alumnado a desarrollar capacidades asociadas con su integración profesional, favoreciendo notablemente la motivación. Paralelamente, la actividad incorpora un trabajo de campo que constituye un elemento básico para que el alumnado se familiarice con la realidad profesional, ya que se solicita el estudio de espacios reales asociados a 
instituciones públicas o privadas, así como la gestión asociada a la presentación y divulgación de la muestra.

Finalmente, con el rompecabezas de grupos, la posibilidad de hacer lecturas parciales de un texto y/o de un libro para ser narradas al resto del grupo, constituye una práctica activa que permite la integración de todo el alumnado en el colectivo que configura la asignatura. En el presente caso, esta integración se basa en el intercambio de ideas y en el desarrollo de capacidades orales.

En definitiva, consideramos que las opciones metodológicas adoptadas han dado buenos resultados. Las mismas, no solo han dado una óptima respuesta a nuestros objetivos para con nuestro alumnado, sino que además se ha logrado el equilibrio necesario entre todas aquellas varibles de las que se disponía (Zabalza, 2003).

\section{Conclusiones}

Antes de hacer alusión a las conclusiones, nos gustaría poner de relieve el peculiar perfil que caracteriza al alumnado universitario del Grado en Bellas Artes, cuestión que resulta fundamental en el proceso de enseñanza-aprendizaje en relación al tema abordado. Al respecto, se puede apuntar que nuestra titulación cuenta con un alumnado que tiene un carácter marcadamente vocacional y que posee una alta motivación.

Si bien este aspecto constituye una notable ayuda en el proceso, cabe decir que si consideramos los resultados obtenidos en los años de docencia impartida, podemos concluir que el alumnado desarrolla de manera más óptima su aprendizaje y su motivación se ve notablemente incrementada si son incorporados los siguientes elementos:

- La utilización de diferentes metodologías docentes.

- La implicación y/o intervención colaborativa y el trabajo en grupo.

- La configuración de canales óptimos de comunicación entre profesor-alumnootros alumnos/as.

- El establecimiento de relaciones entre la adquisición de conocimiento y su aplicación práctica en el ámbito profesional y en contextos reales.

A su vez, la capacidad de motivación del alumnado a la que hemos venido haciendo alusión en el presente texto, refuerza la capacidad de iniciativa de un porcentaje elevado del mismo tal y como se ha podido constatar en los ejemplos seleccionados. En los mismos, un número significativo de alumnos y alumnas no solo resuelve la actividad con el objetivo de obtener una calificación en el marco de la asignatura, sino que realiza una aportación personal que, a su vez, supone una mayor dedicación de tiempo y esfuerzo que no ha sido demandada por el programa de la asignatura o por el docente. Este aspecto, consideramos es destacable en un modelo de enseñanza-aprendizaje en el que se pretende desarrollar capacidades para una formación a lo largo de la vida.

(cc) EY-NC-ND 2016, Universitat Politècnica de València

Congreso In-Red (2016) 
Con respecto a los datos cuantitativos relativos a la aceptación por parte de nuestro alumnado de los modelos metodológicos expuestos, podemos concluir que una amplia mayoría:

- Pone en valor la diversidad de metodologías para la adquisición de capacidades en el proceso de enseñanza-aprendizaje.

- Prefiere la realización de actividades susceptibles de ser llevadas a cabo en escenarios reales.

- Incrementa su motivación ante propuestas con aplicación real en el ámbito profesional.

- Valora positivamente el trabajo colaborativo.

\section{Referencias}

Candela, I. (2007). Sombras de ciudad. Arte y transformación urbana en Nueva York, 1970-1990. Madrid: Alianza Editorial.

DomÉNeCH, F. (1999). Proceso de enseñanza-aprendizaje universitario. Castellón: Universitat Jaume I.

FERNÁNDEZ, A. (2006). "Metodologías activas para la formación de competencias" en Educatio siglo $X X I$, vol. 24, p. 35-56.

GarcíA, D. y AmAnTE, B. (2006). "Algunas experiencias de aplicación del aprendizaje colaborativo y del aprendizaje basado en proyectos" en I Jornadas de Innovación Educativa. Zamora: Escuela Politécnica Superior de Zamora. <http://upcommons.upc.edu/e-prints/handle/2117/9489>. [Consulta: 20 de mayo de 2016].

IMBERNON MUÑOZ, F. Y Medina MOYA, J. L. (2008). Metodología participativa en el aula universitaria. La participación del alumnado. Barcelona: Octaedro/ICE Universitat de Barcelona.

Morales, P. y Landa, V. (2004). “Aprendizaje basado en problemas" en Theoría, vol. 13, p. 145-157.

Zabalza, M.A. (2003). Competencias docentes del profesorado universitario. Madrid: Narcea.

(cc) EY-NC-ND 2016, Universitat Politècnica de València 